\title{
Effect of $\mathrm{TiO}_{2}$ crystalline structure in photocatalytic degradation of phenolic contaminants
}

\author{
Shi-Jane Tsai, Soofin Cheng \\ Department of Chemistry, National Taiwan University, Taipei 106, Taiwan
}

\begin{abstract}
The effect of titanium oxides with various crystalline structures in the photo-decomposition of phenolic contaminants in aqueous solutions was studied. The structural types of titanium oxide under investigation varied from anatase and rutile phases of $\mathrm{TiO}_{2}$ (either commercially available or laboratory-made) to layered and pillared titanates. The photodegradation of several phenolic compounds was examined, such as phenol, 4-chlorophenol, 2,3,5-trichlorophenol and 2,4,6-trichlorophenol. The activities of the catalysts of various structures were compared based on the same titanium content as $0.01 \mathrm{~g} \mathrm{TiO}_{2}$ suspended in $50 \mathrm{ml}$ of aqueous solution containing $1.25 \mathrm{mM}$ phenolic compounds, with an $\mathrm{O}_{2}$ gas flux of $10 \mathrm{ml} / \mathrm{min}$ as oxidant and illumination with $300 \mathrm{~nm}$ UV radiation. The results showed that laboratory-made $\mathrm{TiO}_{2}$ either in the anatase or rutile phase gave better catalytic activity than the commercially available materials when catalysts were properly pretreated. The high activity of the as-prepared lab-made rutile was attributed to the large amount of hydroxy groups present on the catalyst surface, which might stabilize electron-hole pairs. On the other hand, layered titanates, whose charged surface might contribute to the destabilization of electron-hole pairs as well as strong adsorption of phenolic intermediates, showed low photocatalytic activity.
\end{abstract}

\section{Introduction}

Photocatalytic degradation of toxic organic compounds is very promising for the purification and treatment of industrial wastewater [1]. By illumination with light of an energy higher than the band gap of the semiconductors, redox species (conduction band electrons and valence band holes) were considered to generate at the interface and interact directly or through some photosensitizers with organic substrates. Since phenol is commonly used as a solvent or reagent in industrial processes and chlorophenols are

* Corresponding author. Fax: + 886-2-3636359. widely used as herbicides and pesticides, research concerning photodegradation of these phenolic pollutants with semiconductor materials has been growing steadily over the last decade [1-9]. Among the semiconductors being studied, $\mathrm{TiO}_{2}$ is one of the most efficient photocatalysts. The advantage of utilizing $\mathrm{TiO}_{2}$ includes its low cost, radiation stability, and the fact that there is no need to use strong oxidizing agents, such as $\mathrm{O}_{3}$ or $\mathrm{H}_{2} \mathrm{O}_{2}$ [10].

As $\mathrm{TiO}_{2}$ is concerned, several studies have focused on the influence of different crystalline structures. It is generally shown that anatase is more efficient as a photocatalyst than rutile [11-13]. The poor photocatalytic activity of ru- 
tile was proposed due to its higher electron-hole recombination rate [13]. However, Sclafani et al. [14] compared several commercial and homemade $\mathrm{TiO}_{2}$ samples in the photodegradation of phenol and found that the activity of rutile was influenced by its preparation conditions.

Another subject which has received increasing attention is the so-called particle size quantization effect. A blue shift in absorption spectra is usually observed when the size of the semiconductor particles becomes smaller than the Bohr radius of the first exciton state (usually in the range of 1-10 nm) [15]. The quantization was proposed to reduce the rate of hot electron cooling and hence facilitate hot electron transfer to redox acceptors in solution [16]. However, controversial results have been reported regarding the relationship between the degradation rate of organic species and the crystallite size of $\mathrm{TiO}_{2}$. On one hand, $\mathrm{TiO}_{2}$ of nano-particle sizes was reported to enhance the photocatalytic activities in hydrogenation of propyne [17] and decomposition of 2-propanol and n-carboxylic acids [18]. On the other hand, the degradation rate of trichloroethene was found to increase with the crystallite size of anatase, while no obvious correlation was deduced from the degradation rates of water-soluble organic compounds and the particle size [12].

Other than the commonly known three-dimensional crystalline structures of anatase, rutile and brookite, titanium oxide also forms a series of two-dimensional layered titanates [19]. In a previous study, we found that layered tetratitanate, $\mathrm{K}_{2} \mathrm{Ti}_{4} \mathrm{O}_{9}$, has a $0.38 \mathrm{eV}$ blue shift of band gap relative to anatase although the average particle size of the former is larger [20]. This large band gap is a result of space confinement of the titanate sheets by interlayer potassium ions. Such a structural confinement leads to one-dimensional quantization and the formation of discrete electronic states in contrast to the continuum of states present in the three-dimensional crystalline $\mathrm{TiO}_{2}$ [16]. Nevertheless, the photocatalytic activity of $\mathrm{K}_{2} \mathrm{Ti}_{4} \mathrm{O}_{9}$ in phenol decomposition was found to be much lower than that of anatase, implying that the quantization effect played little role in the activity. In this study, we extend our studies to photodecomposition of 4-chlorophenol and trichlorophenols. In addition, the photocatalytic activities of lab-made $\mathrm{TiO}_{2}$ of both anatase and rutile phases were examined in order to understand the nature of the active sites.

\section{Experimental}

\subsection{Preparation of catalysts}

Reagent grade chemicals were used as purchased without further purification. Laboratory-made $\mathrm{TiO}_{2}$ of anatase phase (LA) was prepared following the procedures mentioned in Ref. [21]. Rutile phase (LR) was prepared by boiling a diluted $\mathrm{TiOCl}_{2}$ solution $(0.4$ $\mathrm{M})$ at $80-90^{\circ} \mathrm{C}$ for $3 \mathrm{~h}$, according to the recipe given by Cavani et al. [22]. The resultant solids were filtered, washed with double deionized water until free of $\mathrm{Cl}^{-}$ions, and dried at room temperature. The catalysts after calcination at various temperatures for $3 \mathrm{~h}$ were labelled LA- $t$, or LR- $t$, where ' $t$ ' designates the calcination temperature in ${ }^{\circ} \mathrm{C}$. Layered tetratitanate $\left(\mathrm{K}_{2} \mathrm{Ti}_{4} \mathrm{O}_{9}\right)$ and zirconia-pillared trititanate $(\mathrm{Zr}-$ $\mathrm{Ti}_{3} \mathrm{O}_{7}$ ) were prepared and identified as described in Ref. [20].

\subsection{Characterization techniques}

The BET surface areas were determined by physical adsorption of $\mathrm{N}_{2}$ at liquid $\mathrm{N}_{2}$ temperature in a volumetric system. The powder XRD patterns were examined with a Scintag X2 automated powder diffractometer using $\mathrm{Cu} \mathrm{K} \alpha$ radiation. FT-Raman spectra were recorded using a BOMEM MB155 FT-IR/Raman spectrometer with a Nd-YAG laser (1064 nm). Diffuse reflectance UV-VIS spectra of powder samples were determined with a Shimadzu UV-2101PC spectrometer. The fluorescence lifetimes of solid 
catalysts were determined with time-resolved spectroscopy using $355 \mathrm{~nm}$ light source generated from a Nd-YAG laser and detecting at 450 nm.

\subsection{Photocatalytic activities}

The apparatus for photocatalysis was described previously [20]. The amount of catalyst used was based on the same Ti content as 0.01 $\mathrm{g} \mathrm{TiO}_{2}$. The catalyst in powder form was suspended in $50 \mathrm{ml}$ aqueous solution of $1.25 \mathrm{mM}$ phenolic compounds, $\mathrm{O}_{2}$ gas of $10 \mathrm{ml} / \mathrm{min}$ was the oxidant, and $300 \mathrm{~nm}$ UV radiation was the light source. The outlet gases were directed through a two-stage bubbling trap containing saturated $\mathrm{Ba}(\mathrm{OH})_{2}$ solution. $\mathrm{CO}_{2}$ yield was determined based on the weight of $\mathrm{BaCO}_{3}$ precipitated. Products retained in the aqueous solution after certain radiation period were separated with an Rtx-5 column and identified with a flame ionization detector (Hewlett Packard 5890 GC).

\section{Results and discussion}

\subsection{Catalyst characterization}

The crystalline structures of lab-made $\mathrm{TiO}_{2}$ of anatase and rutile phases were identified by $\mathrm{X}$-ray diffractograms. Fig. 1 shows that a single phase of either anatase or rutile was formed as expected from different synthetic procedures. Moreover, the crystallinity of each phase increases as the calcination temperature increases, as indicated by the decrease in the full-widthat-half-maxima (fwhm) of the peaks. On the other hand, Raman spectroscopy was found more sensitive in detecting structures of poor crystallinity. Fig. 2 compares the FT-Raman spectra of the above samples with those of commercial ones in the region of $200-800 \mathrm{~cm}^{-1}$. The characteristic vibrational peaks of anatase appeared at 638,515 and $396 \mathrm{~cm}^{-1}$, and those of rutile at 610 and $448 \mathrm{~cm}^{-1}$, which are consis-
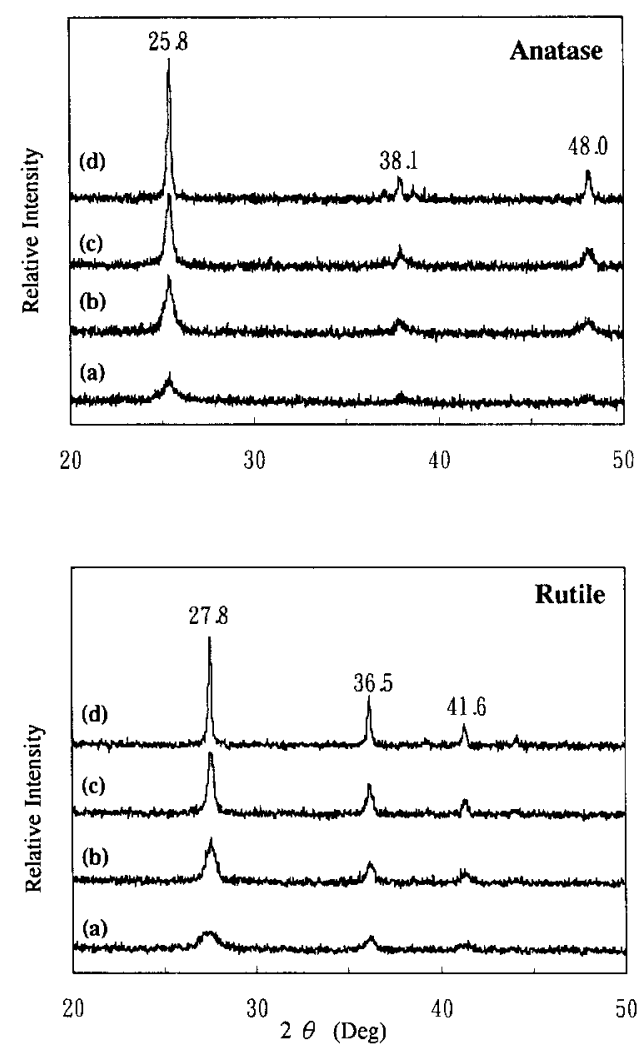

Fig. 1. XRD patterns of lab-made anatase and rutile $\mathrm{TiO}_{2}$ : (a) as-prepared, and after calcination at (b) $400^{\circ} \mathrm{C}$, (c) $550^{\circ} \mathrm{C}$, and (d) $700^{\circ} \mathrm{C}$.

tent with those reported in literature [23]. Similar to the XRD patterns, the fwhm of these Raman peaks decreases with calcination temperature, indicating an increase in crystallinity. However, the spectrum of lab-made rutile after calcination at $400^{\circ} \mathrm{C}$ shows that two small peaks at 635 and $395 \mathrm{~cm}^{-1}$ appeared as shoulders of the two main absorptions and a small peak appeared at ca. $515 \mathrm{~cm}^{-1}$. These peaks, which are coincident with the characteristic peaks of anatase, disappeared after the samples were calcined at $550^{\circ} \mathrm{C}$ or higher. Because anatase is transformed to rutile at high temperatures, these results imply that both as-synthesized and $400^{\circ} \mathrm{C}$-calcined rutile samples should contain small amounts of anatase structure, but the structure was so amorphous that XRD could not detect it.

The BET surface areas and physical data of the diffuse reflectance UV-Vis. spectra of the 

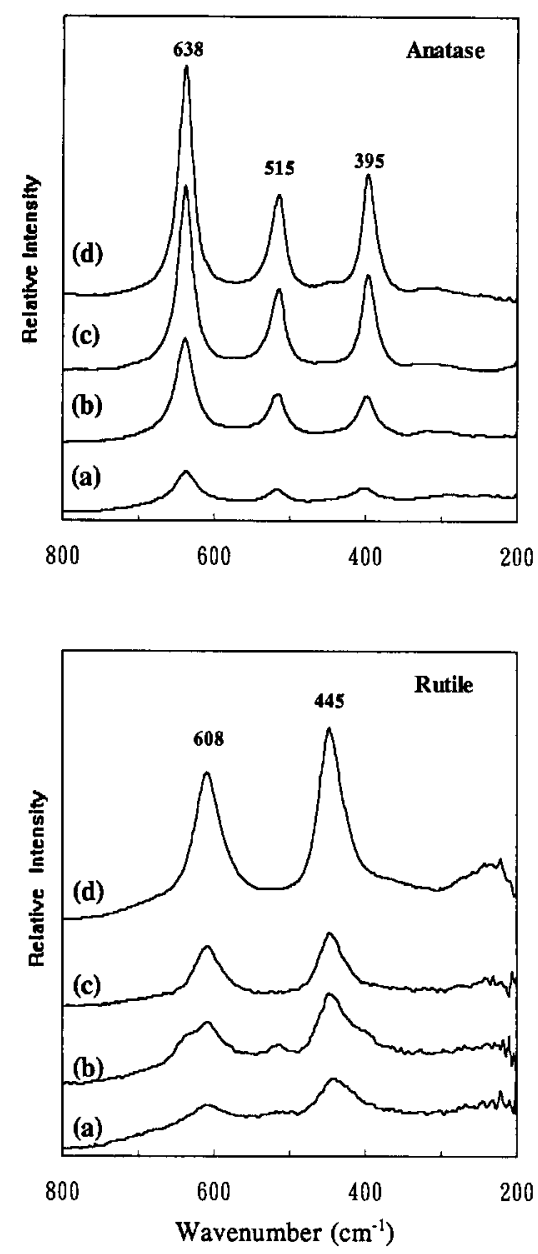

Fig. 2. FT-Raman spectra of anatase and rutile $\mathrm{TiO}_{2}$ : (a) as-prepared, and after calcination at (b) $400^{\circ} \mathrm{C}$ and (c) $700^{\circ} \mathrm{C}$, in comparison to that of (d) commercial sample.

catalysts are tabulated in Table 1. Lab-made anatase and rutile have relatively high BET surface area, 236 and $141 \mathrm{~m}^{2} / \mathrm{g}$, respectively. Although the surface areas decrease markedly with calcination temperature, the lab-made $\mathrm{TiO}_{2}$ samples have higher surface areas than the commercial ones, up to the calcination temperature of $550^{\circ} \mathrm{C}$. On the other hand, the layered titanate, $\mathrm{K}_{2} \mathrm{Ti}_{4} \mathrm{O}_{9}$, has very low surface area, while the zirconia-pillared titanate has a much larger surface area due to the propped interlayer space by the pillars.

The band-gaps of the samples were determined based on the absorption threshold of their
UV-Vis. spectra. As expected, all rutile samples have lower band-gaps than anatase. However, the as-synthesized $\mathrm{TiO}_{2}$ samples show an obvious blue-shift of band-gap relative to that of the commercial ones. Since the former have higher surface areas, implying that they have smaller particle sizes, the blue shift in band-gap is consistent with the particle size quantization effect. After calcination, the lab-made $\mathrm{TiO}_{2}$ samples sintered and became larger particles. As a result, a red shift of the band gap was observed. On the other hand, layered $\mathrm{K}_{2} \mathrm{Ti}_{4} \mathrm{O}_{9}$, with low surface area and large particle size, has a $0.38 \mathrm{eV}$ blue-shift of band-gap relative to anatase. This result suggests that there is no covalent interaction between adjacent titanate layers and the interlayer $\mathrm{K}^{+}$ions confine the titanate sheets in such a way as to lead to one-dimensional quantization. However, the band gap of zirconia-pillared titanate shifts closer to that of anatase, due to the formation of cross-linking covalent structures between the pillars and titanate layers. Among all these catalysts, commercial rutile has the smallest bandgap, while $\mathrm{K}_{2} \mathrm{Ti}_{4} \mathrm{O}_{9}$ has the largest band-gap.

\subsection{Photocatalytic decomposition of phenolic compounds}

Fig. 3 shows the photodegradation rates of phenol catalyzed by sample LA- 400 in the first

Table 1

BET surface areas and the data of diffuse reflectance UV-Vis. spectra

\begin{tabular}{lrlll}
\hline Catalyst & $\mathrm{SA} / \mathrm{m}^{2} \mathrm{~g}^{-1}$ & Band-gap $/ \mathrm{eV}$ & $I_{300 \mathrm{~nm}}$ & $I_{350 \mathrm{~nm}}$ \\
\hline Anatase (Merck) & 34 & 3.08 & 0.921 & 0.865 \\
LA-25 & 236 & 3.15 & 0.985 & 0.812 \\
LA-400 & 95 & 3.11 & 0.953 & 0.909 \\
$\mathrm{LA}-550$ & 59 & 3.09 & 0.927 & 0.899 \\
LA-700 & 17 & 3.08 & 0.894 & 0.875 \\
Rutile (Janssen) & 6 & 2.84 & 0.873 & 0.926 \\
LR-25 & 141 & 3.02 & 1.009 & 0.884 \\
LR-400 & 74 & 3.02 & 1.013 & 0.952 \\
LR-550 & 29 & 3.01 & 0.996 & 0.952 \\
LR-700 & 23 & 3.00 & 0.976 & 0.945 \\
$\mathrm{~K}_{2} \mathrm{Ti}_{4} \mathrm{O}_{9}$ & 7 & 3.46 & 0.744 & 0.168 \\
$\mathrm{Zr}_{4}-\mathrm{Ti}_{3} \mathrm{O}_{7}$ & 162 & 3.12 & 0.941 & 0.619 \\
\hline
\end{tabular}




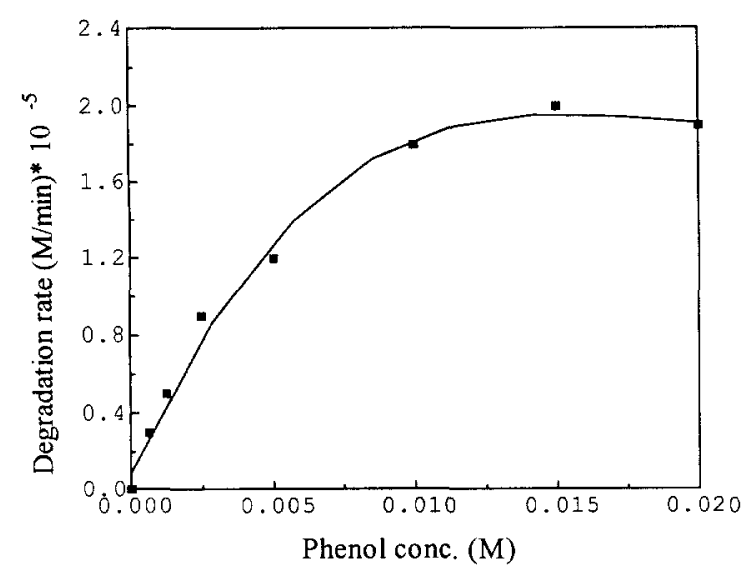

Fig. 3. Photodegradation rate (first hour) of phenol as a function of phenol concentration.

hour as a function of phenol concentration. We have applied the Langmuir-Hinshelwood kinetic model to treat these data. The rate is independent of phenol concentration when the latter is greater than $0.01 \mathrm{M}$. Accordingly, in solutions of $1.25 \mathrm{mM}$ phenol, the catalyst surface is not saturated with reactant and this concentration was used hereafter for examining photocatalytic activities of all the catalysts.

Table 2 demonstrates the influence of anatase $\mathrm{TiO}_{2}$ catalyst, $300 \mathrm{~nm}$ radiation and oxygen effluent on the degradation of phenol and 4chlorophenol. The results show that $300 \mathrm{~nm}$ radiation is essential for both phenol and 4-chlorophenol degradation. Moreover, phenol conversion decreases markedly when lacking any of these three components, while 4-chlorophenol degradation was highly efficient as long as 300 $\mathrm{nm}$ radiation was used, even without $\mathrm{TiO}_{2}$ catalyst or when $\mathrm{O}_{2}$ was replaced by $\mathrm{N}_{2}$ as effluent.
For all these conditions, only very small amounts of the reactants were completely oxidized to $\mathrm{CO}_{2}$ and therefore most of the phenolic reactants was converted to some intermediate species. Nevertheless, the combination of all three reaction components did increase $\mathrm{CO}_{2}$ yield.

Fig. 4 compares phenol conversion and $\mathrm{CO}_{2}$ yield over various titanium oxide catalysts. After $1 \mathrm{~h}$ irradiation, commercial anatase gives the highest phenol conversion although the $\mathrm{CO}_{2}$ yield is relatively low. After $6 \mathrm{~h}$ irradiation, the $\mathrm{CO}_{2}$ yield reached a value of $55.4 \%$ and phenol disappeared completely. On the other hand, commercial rutile gave much lower phenol conversion $(56.5 \%)$ and $\mathrm{CO}_{2}$ yield $(20.5 \%)$. In contrast, the catalytic activities of lab-made anatase and rutile varied with calcination temperature. Although neither of them lead to $100 \%$ phenol conversion as that observed over commercial anatase, higher $\mathrm{CO}_{2}$ yields were obtained over LA-400, LR-25 and LR-400. Most surprisingly, the lab-made rutile (LR-25) gave the highest activity in complete decomposition of phenol to $\mathrm{CO}_{2}(75.4 \%)$. The activity, however, decreased with increase of calcination temperature. A similar trend was observed for lab-made anatase, except the one dried at ambient temperature gave the lowest activity. The identification of the intermediates is difficult due to their low concentration. However, our previous studies found that ethers were present in the gaseous products and that catechol and hydroquinone were observed in solution when a more concentrated $(0.01 \mathrm{M})$ phenol solution was used [20].

Table 2

Effect of reaction conditions on the degradation of phenol and 4-chlorophenol a

\begin{tabular}{|c|c|c|c|c|c|c|}
\hline \multicolumn{3}{|l|}{ Raction conditions } & \multicolumn{2}{|l|}{ Phenol } & \multicolumn{2}{|l|}{ 4-CP } \\
\hline Anatase $\mathrm{TiO}_{2}(\mathrm{~g})$ & Light & Effluent $(10 \mathrm{ml} / \mathrm{min})$ & Conv. (\%) & $\mathrm{CO}_{2}$ yield $(\%)$ & Conv. $(\%)$ & $\mathrm{CO}_{2}$ yield $(\%)$ \\
\hline 0.01 & $300 \mathrm{~nm}$ & $\mathrm{O}_{2}$ & 65.3 & 5.1 & 100 & 8.1 \\
\hline 0.01 & - & $\mathrm{O}_{2}$ & 4.3 & 2.4 & 26.7 & 2.4 \\
\hline 0.01 & $300 \mathrm{~nm}$ & $\mathrm{~N}_{2}$ & 10.6 & 3.5 & 97.4 & 1.6 \\
\hline 0 & $300 \mathrm{~nm}$ & $\mathrm{O}_{2}$ & 21.6 & 2.4 & 98.8 & 1.9 \\
\hline
\end{tabular}

a Initial concentrations of phenol and 4-chlorophenol were $1.25 \mathrm{mM}$, and the data were taken after reaction for $1 \mathrm{~h}$. 


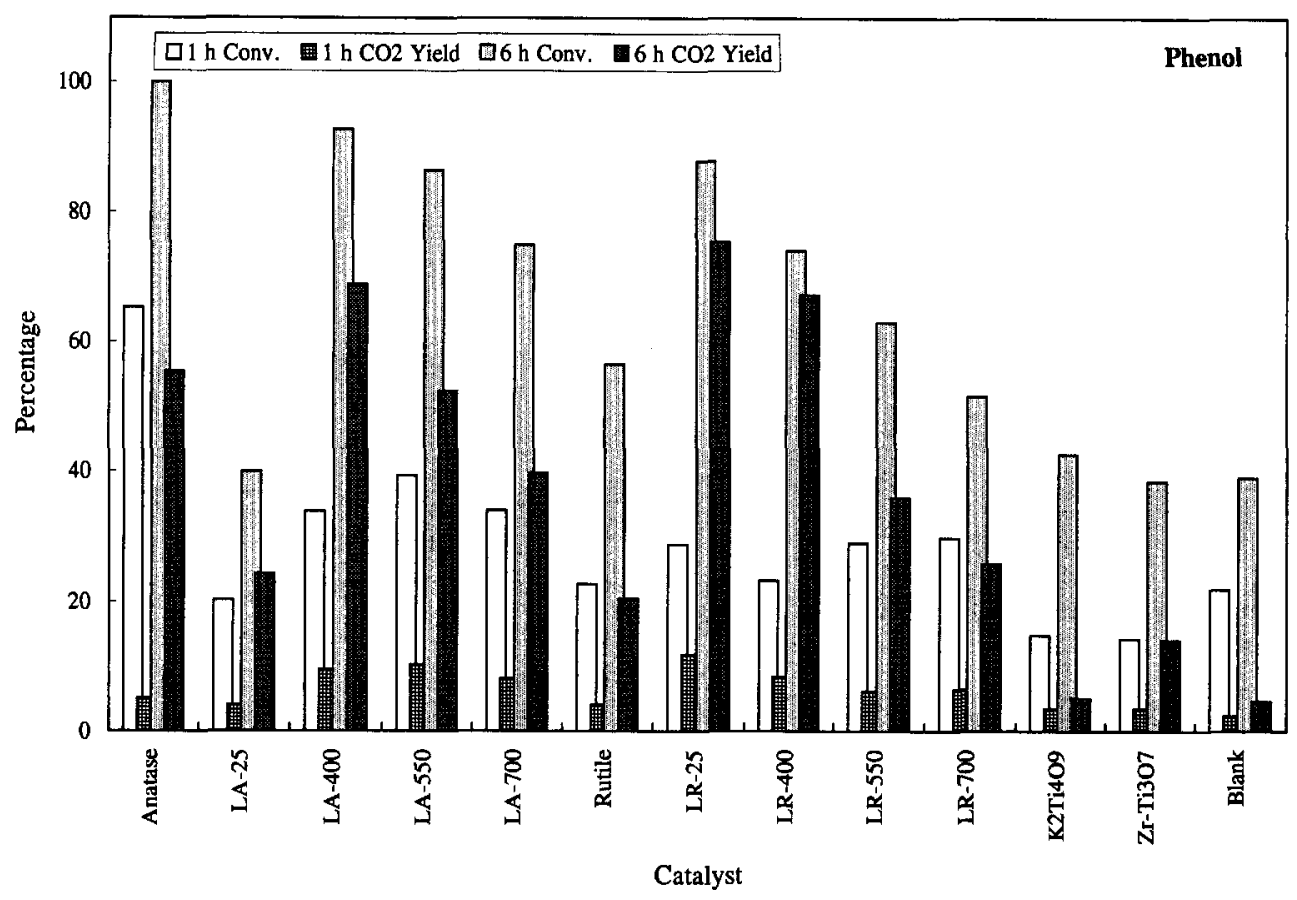

Fig. 4. Photodegradation of phenol over titanium oxide of various structures.

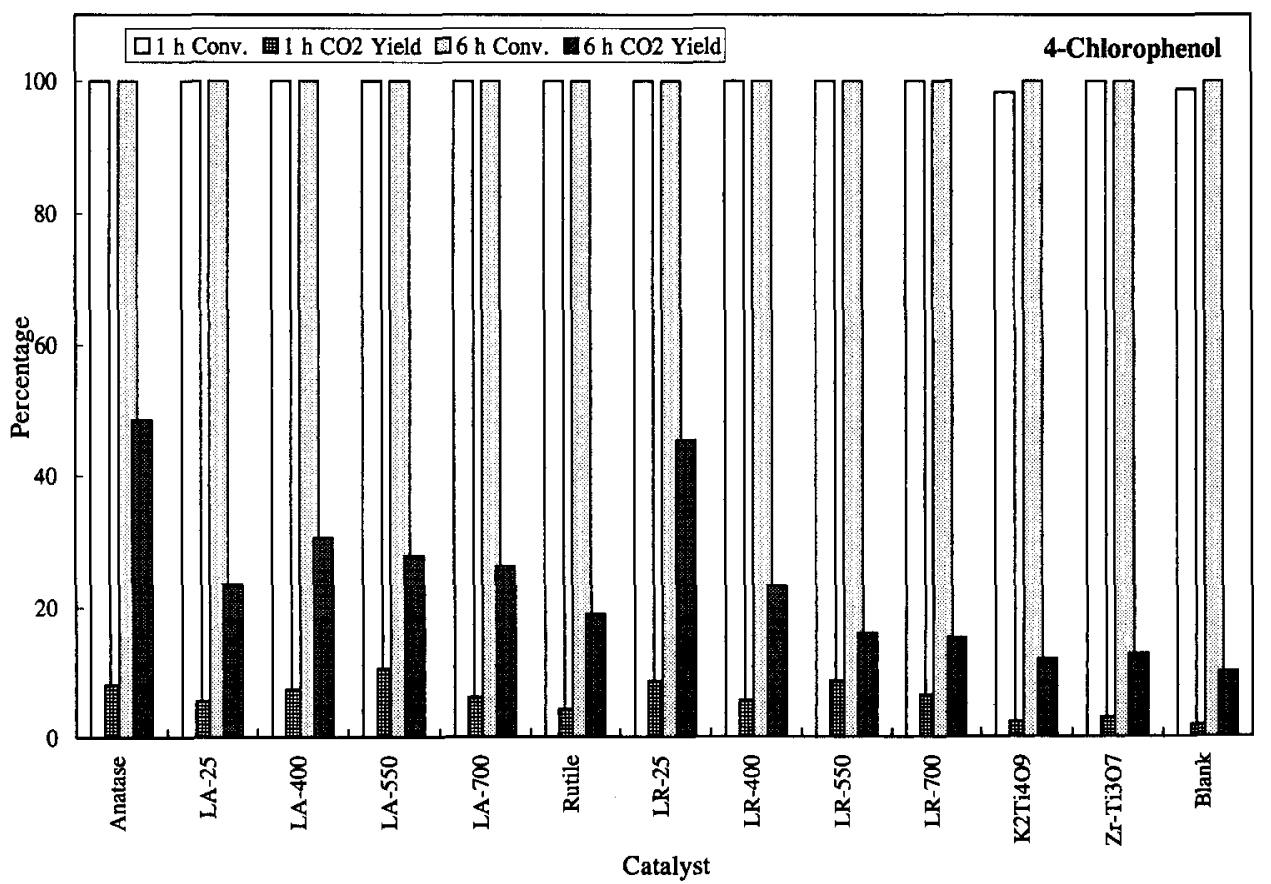

Fig. 5. Photodegradation of 4-chlorophenol over titanium oxide of various structures. 


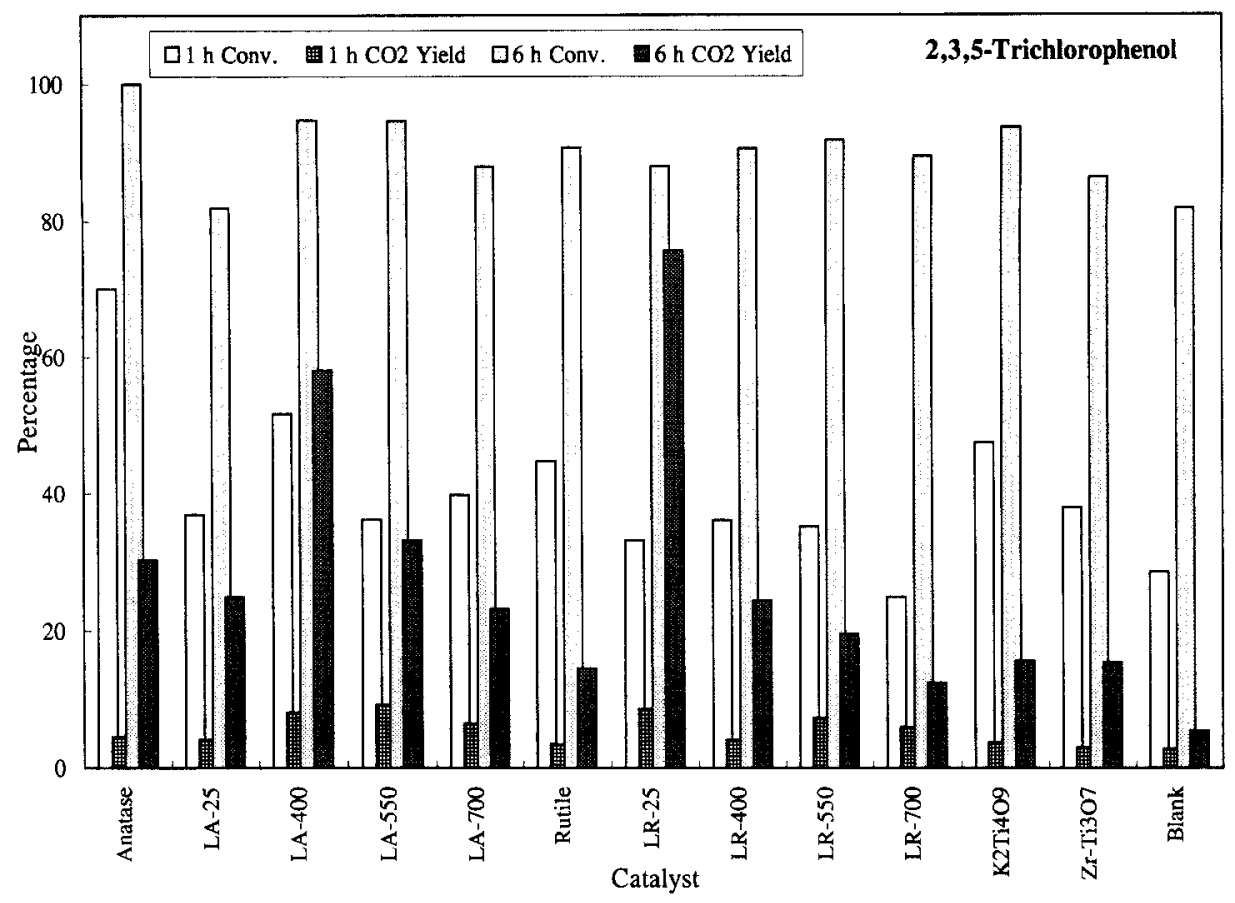

Fig. 6. Photodegradation of 2,3,5-trichlorophenol over titanium oxide of various structures.

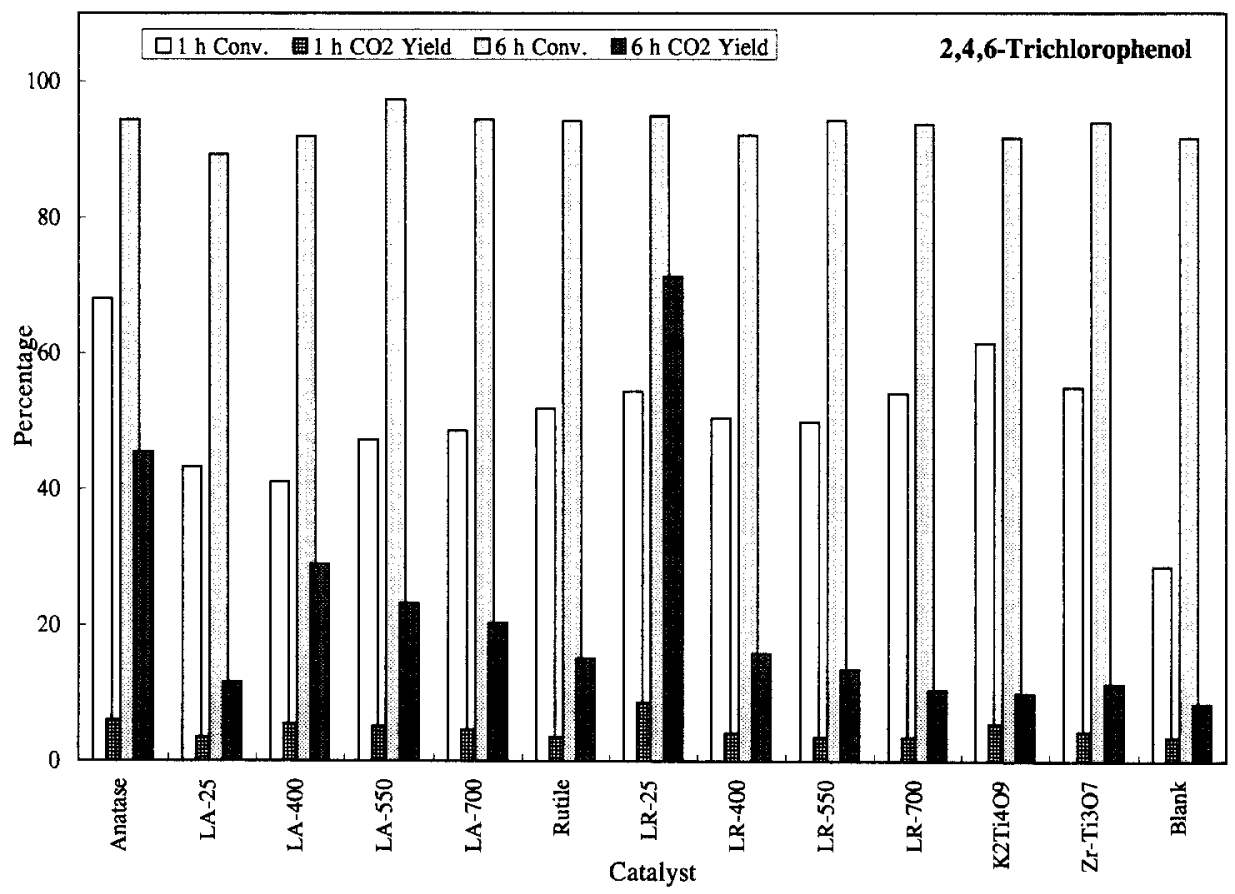

Fig. 7. Photodegradation of 2,4,6-trichlorophenol over titanium oxide of various structures. 
In contrast to the above mentioned three-dimensional $\mathrm{TiO}_{2}$ catalysts, $\mathrm{K}_{2} \mathrm{Ti}_{4} \mathrm{O}_{9}$ and zirconia-pillared titanate both of layered structures showed extremely low activity in phenol degradation. These results suggest that one-dimensional quantization, although increasing the band-gap of the powder catalyst, has little effect on the photocatalytic activity.

Fig. 5 summarizes the results of photodegradation of 4-chlorophenol. Different from phenol, 4-chlorophenol disappeared almost completely after $1 \mathrm{~h}$ of irradiation, even without the catalysts. However, $\mathrm{CO}_{2}$ yields were very low (2-10\%) and 1,4-hydroquinone was detected as an intermediate in solution over most of the catalysts. The change of the irradiated solution from transparent to yellow-brown colors was an indication that oligomers were probably formed. The great discrepancy between 4-chlorophenol conversion and $\mathrm{CO}_{2}$ yield was also observed by Hoffmann et al. [8], who also reported several other intermediates. After $6 \mathrm{~h}$ irradiation, commercial anatase and lab-made rutile (LR-25) gave the highest $\mathrm{CO}_{2}$ yields, $48.6 \%$ and $45.4 \%$, respectively, while other catalysts gave $\mathrm{CO}_{2}$ yields lower than $30 \%$. Based on the $\mathrm{CO}_{2}$ yields, the catalytic activities of these titanium oxide catalysts in 4-chlorophenol decomposition vary in a pattern similar to that of phenol.

Fig. 6 and Fig. 7 show the results of photodegradation of 2,3,5- and 2,4,6-trichlorophenols, respectively. Lab-made rutile (LR-25) is the most efficient one among all the studied catalysts for complete decomposition of both trichlorophenols to $\mathrm{CO}_{2}$, while layered titanates are among the catalysts of lowest activities.

\subsection{Factors affecting the photocatalytic activity}

In order to examine the effect of surface area, a series of lab-made rutile samples calcined at different temperatures were used as photocatalysts in phenol decomposition based on the weights which gave the same total surface area. Table 3 shows that the activity still decreases
Table 3

Results of photodegradation of $1.25 \mathrm{mM}$ phenol over lab-made rutile $\mathrm{TiO}_{2}$ samples after $6 \mathrm{~h}$ irradiation

\begin{tabular}{lllll}
\hline Catalyst & $\begin{array}{l}\text { Wt. of } \\
\text { catalyst }(\mathrm{g})\end{array}$ & $\begin{array}{l}\text { Total SA } \\
\left(\mathrm{m}^{2}\right)\end{array}$ & $\begin{array}{l}\text { Conv. } \\
(\%)\end{array}$ & $\begin{array}{l}\mathrm{CO}_{2} \text { yield } \\
(\%)\end{array}$ \\
\hline LR-25 & 0.0100 & 1.41 & 87.9 & 75.4 \\
LR-400 & 0.0191 & 1.41 & 83.6 & 63.0 \\
LR-400 & 0.0100 & 0.74 & 74.1 & 67.3 \\
LR-700 & 0.0613 & 1.41 & 63.3 & 42.2 \\
LR-700 & 0.0100 & 0.23 & 51.6 & 25.9 \\
\hline
\end{tabular}

with calcination temperature for catalysts of the same total surface area. Moreover, for any of the specific catalysts, the phenol conversion was found to increase with the weight or total surface area of the catalyst but not in direct proportion. As for the $\mathrm{CO}_{2}$ yield, no simple relationship with surface area can be drawn from the data.

Sclafani et al. [14] attributed the high activities of lab-made rutile to its large amount of hydroxyl groups on the surface, and proposed that they might trap the holes in the valence band and enhance the chemisorption of $\mathrm{O}_{2}$ molecules in the conduction band. Fig. 8 compares the diffuse reflectance infrared spectra of anatase and rutile for both commercial and labmade samples. The commercial rutile, which is highly crystalline and has low surface area, has no absorption in the $\mathrm{O}-\mathrm{H}$ stretching vibration region, implying no hydroxyl groups are present on the surface. In contrast, lab-made rutile (LR25) has a large broad absorption with a maximum at ca. $3257 \mathrm{~cm}^{-1}$. After calcined at $400^{\circ} \mathrm{C}$, the intensity obviously decreases and three peaks at 3668,3318 and $3073 \mathrm{~cm}^{-1}$ can be resolved. The intensity of these peaks decreases further with an increase of calcination temperature. Since the photocatalytic activity of lab-made rutile decreases with calcination temperature, the activity seems to have a direct correlation with the amount of $\mathrm{O}-\mathrm{H}$ groups on the surface. This can also explain why commercial rutile has very low photocatalytic activity. On the other hand, both commercial and lab-made anatase samples have rather strong absorptions in the 

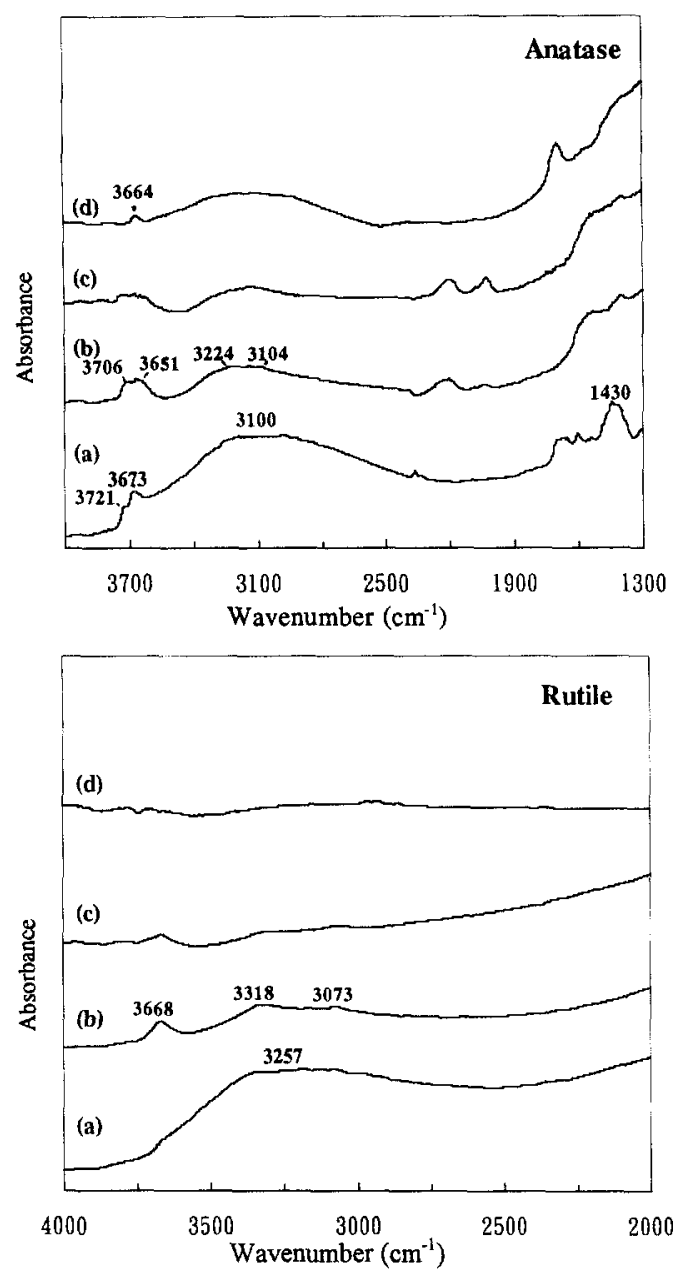

Fig. 8. Diffuse reflectance IR spectra of anatase and rutile $\mathrm{TiO}_{2}$ : (a) as-prepared, and after calcination at (b) $400^{\circ} \mathrm{C}$ and (c) $550^{\circ} \mathrm{C}$, in comparison to that of $(\mathrm{d})$ commercial sample.

$\mathrm{O}-\mathrm{H}$ stretching region. Other than a broad band at ca. $3100 \mathrm{~cm}^{-1}$ and two sharp absorptions at 3673 and $3721 \mathrm{~cm}^{-1}$, the as-prepared anatase (LA-25) also has an additional peak at ca. 1440 $\mathrm{cm}^{-1}$, which is the characteristic absorption of ammonium ions. Hence, the relatively low photocatalytic activity of the as-prepared anatase is likely due to the residue of $\mathrm{NH}_{4}^{+}$ions on the surface. The activity increased coincidently with the removal of ammonium ions from the surface after the sample was calcined at high temperatures.

The fluorescence lifetimes of the catalysts were measured by using time-resolved spec- troscopy. Table 4 shows that the lifetimes vary from 0.18 to $0.45 \mu \mathrm{s}$. Generally speaking, those catalysts of higher photocatalytic activities have longer lifetimes. Thus, the lifetime of lab-made rutile $(0.40 \mu \mathrm{s})$ is in a close range as those of commercial anatase $(0.45 \mu \mathrm{s})$ and LA-400 (0.46 $\mu \mathrm{s})$, while those of commercial rutile, layered titanates, as well as LR-700 are about a halfvalue shorter. The short fluorescence lifetime of commercial rutile is likely a result of the high recombination rate of electron-hole pairs, as proposed in literature [11]. If that is the case, then the long lifetime of as-prepared rutile (LR25) is probably because its surface hydroxyl groups might stabilize the holes in the valence band and the electrons in the conduction band from recombination. As surface dehydroxylation is accompanied with calcination of the catalyst at elevated temperatures, the fluorescence lifetime decreases. However, the as-prepared anatase, which has a large IR absorption in the O-H stretching region, has shorter fluorescence lifetime as well as relatively low photocatalytic activity. Therefore, surface $\mathrm{NH}_{4}^{+}$ions probably play a role in destabilizing the photoinduced exited state.

Titanate catalysts (both layered and pillared structures) showed low photocatalytic activities as well as short fluorescence lifetimes. Regarding to the quantization effect, it is generally considered that large band gaps reduce the rate of hot electron cooling and hence facilitate hot electron transfer to redox acceptors in solution [16]. In contrast, $\mathrm{K}_{2} \mathrm{Ti}_{4} \mathrm{O}_{9}$, which has the largest

Table 4

Results of fluorescence lifetime measurements

\begin{tabular}{ll}
\hline Catalyst & $\tau(\mu \mathrm{s})$ \\
\hline Anatase (Merck) & 0.45 \\
LA-25 & 0.34 \\
$\mathrm{LA}-400$ & 0.46 \\
$\mathrm{LA}-700$ & 0.32 \\
Rutile (Janssen) & 0.20 \\
LR-25 & 0.40 \\
$\mathrm{LR}-700$ & 0.18 \\
$\mathrm{~K}_{2} \mathrm{Ti}_{4} \mathrm{O}_{9}$ & 0.26 \\
$\mathrm{Zr}-\mathrm{Ti}_{3} \mathrm{O}_{7}$ & 0.23 \\
\hline
\end{tabular}


band gap among all studied catalysts, has a relatively short fluorescence lifetime and low photocatalytic activity. This is attributed to surface $\mathrm{K}^{+}$ions destabilizing the hot electrons, a case similar to $\mathrm{NH}_{4}^{+}$ions on the surface of LA-25. In addition, our previous study using a more concentrated phenol reactant showed that the low photocatalytic activity of the catalyst was due to more coke formed on the surface [20]. This coke originates from the strong interaction between phenolic intermediates and the charged surfaces. As a result, ionic species present on the surface should lower the photocatalytic activity of titanium oxide by reducing the lifetime of hot electrons as well as coking the surface with phenolic intermediates.

\subsection{Mechanism of photodegradation}

Studies of reaction mechanisms of photodegradation of organic pollutants present in aqueous solutions encounter great difficulties mainly due to the low concentrations of the reactants usually used in order to mimic the real environment. Nevertheless, in the photodecomposition of phenol, it is generally accepted that the primary step is the hydroxylation of the phenyl ring $[4,5,10]$, where the hydroxy radical is generated either through the combination of water molecule and valence band holes or that of adsorbed oxygen and conduction band electrons. Hence, many hydroxylated phenol compounds, such as catechol (CC), hydroquinone (HQ), hydroxyhydroquinone (HHQ), benzoquinone (BQ), etc., have been suggested to be the intermediates [5]. Acetate and formate were also proposed to be formed in the initial stage of degradation [10]. Our previous study however detected dimethyl ether and diethyl ether as gaseous products and BQ as the main component of coke [20]. The latter confirms that hydroxylation of the phenyl ring is the primary step during photodegradation. The low molecular weight oxygenated species therefore should be the products of further oxidation of the hydroxylated phenol intermediates.
Under photocatalytic conditions, hydroxy radicals were also proposed to be involved in the primary step of 4-chlorophenol (4-CP) degradation [24]. The resultant dihydroxylchlorocyclohexadienyl radical subsequently decomposes into $\mathrm{HQ}$ and $\mathrm{Cl} \cdot$ radicals. Indeed, HQ was detected in the initial stage of 4-CP degradation over most of the catalysts in this study. On the other hand, although HQ was reported also to be formed by direct photolysis of 4-CP, it was not detected in our blank experiment (no catalyst). However, 4-CP was found to disappear much faster than phenol or trichlorophenols as long as the radiation was $300 \mathrm{~nm}$. By contrast, the $\mathrm{CO}_{2}$ yields in the photodegradation of chlorophenols are generally lower than that of phenol. These results imply that $\mathrm{Cl}$ - radicals probably inhibit the further oxidation of intermediate species through capture of conduction band electrons and formation of $\mathrm{Cl}^{-}$ions. Moreover, $\mathrm{CO}_{2}$ yields in degradation of trichlorophenols over various titanium oxide catalysts vary in a pattern similar to those of 4-CP. The similarity implies that the primary steps for degradation of chlorophenols are all similar and involve hydroxylation of phenyl rings. Nevertheless, it is beyond our understanding why lab-made rutile (LR-25) shows uniquely high $\mathrm{CO}_{2}$ yields in trichlorophenol degradation.

\section{Conclusions}

In summary, lab-made anatase and rutile demonstrated better photocatalytic activities in decomposition of phenolic contaminants than commercially available ones. The activities however were found to depend on the calcination temperature of the catalysts. Moreover, the as-prepared lab-made rutile showed greatest activities in complete oxidation of phenol and chlorophenols to $\mathrm{CO}_{2}$. The activity was attributed to the presence of large amounts of $\mathrm{O}-\mathrm{H}$ groups on the surface, which seem to stabilize the holes in the valence band and electrons in the conduction band from recom- 
bination. In contrast, charged species present on the catalyst surface, such as $\mathrm{NH}_{4}^{+}$and $\mathrm{K}^{+}$, tend to destabilize the electron-hole pairs and hence lower the catalytic activity as well as fluorescence lifetime. As a result, layered titanates showed low photocatalytic activities. On the other hand, the primary step of photodegradation of the phenolic contaminants involves hydroxylation of phenyl rings with $\cdot \mathrm{OH}$ radicals. Surface charged species might also contribute to coking the catalyst surface, resulting from strong adsorption of the hydroxylated phenolic intermediates. Our results also demonstrated that size quantization effects, which is generally correlated with variation of the band-gap, has no role in the photodegradation of phenolic contaminants.

\section{Acknowledgements}

Financial support from the National Science Council of Taiwan, Republic of China is gratefully acknowledged.

\section{References}

[1] D.F. Ollis and H. Al-Ekabi eds., Photocatalytic Purification and Treatment of Water and Air (Elsevier, Amsterdam, 1993).

[2] S. Chatterjee, S. Sarkar and S.N. Bhattacharyya, J. Photochem. Photobiol. A: Chem. 81 (1994) 199.
[3] R.W. Matthews, J. Phys. Chem. 91 (1987) 3328.

[4] R.W. Matthews and S.R. McEvoy, J. Photochem. Photobiol. A: Chem. 64 (1992) 231.

[5] K.-I. Okamoto, Y. Yamamoto, H. Tanaka and M. Tanaka, Bull. Chem. Soc. Jpn. 58 (1985) 2015.

[6] H. Al-Ekabi and N. Serpone, J. Phys. Chem. 92 (1988) 5726.

[7] G. Al-Sayyed, J.-C. D'Oliverira and P. Pichat, J. Photochem. Photobiol. A: Chem. 58 (1991) 99.

[8] M.R. Hoffmann, S.T. Martin, W. Choi and D.W. Bahnemann, Chem. Rev. 95 (1995) 69.

[9] A. Mills and P. Sawunyama, J. Photochem. Photobiol. A: Chem. 84 (1994) 305.

[10] A. Braun, In: eds. E. Pelizzetti and M. Schiavello, Photochemical Conversion and Storage of Solar Energy (Kluwer, Dordrecht, 1991) p. 551.

[11] S.-I. Nishimoto, B. Ohtani, H. Kajiwara and T. Kagiya, J. Chem. Soc., Faraday Trans. 181 (1985) 61.

[12] K. Tanaka, T. Hisanaga and A.P. Rivera, In: eds. D.F. Ollis and H. Al-Ekabi, Photocatalytic Purification and Treatment of Water and Air (Elsevier, Amsterdam, 1993) p. 169.

[13] M.A. Fox and M.T. Dulay, Chem. Rev. 93 (1993) 541.

[14] A. Sclafani, L. Palmisano and M. Schiavello, J. Phys. Chem. 94 (1990) 829.

[15] A. Hagfeldt and M. Gratzel, Chem. Rev. 95 (1995) 49.

[16] A.J. Nozik, In: eds. D.F. Ollis and H. Al-Elabi, Photocatalytic Purification and Treatment of Water and Air (Elsevier, Amsterdam, 1993) p. 39.

[17] M. Anpo, T. Shima, S. Kodama and Y. Kubokawa, J. Phys. Chem. 91 (1987) 4305.

[18] H. Yoneyama, S. Haga and S. Yamanaka, J. Phys. Chem. 93 (1989) 4833.

[19] B. Raveau, Rev. Inorg. Chem. 9 (1987) 37.

[20] S. Cheng, S.-J. Tsai and Y.-F. Lee, Catal. Today 26 (1995) 87.

[21] C.-S. Chang, S.-J. Jong and Cheng, J. Chin. Chem. Soc. 42 (1995) 31.

[22] F. Cavani, E. Foresti, F. Parrinello and F. Trifiro, Appl. Catal. 38 (1988) 311.

[23] G. Busca, G. Ramis, J.M.G. Amores, V.S. Escribano and P. Piaggio, J. Chem. Soc., Faraday Trans. 90 (1994) 3181.

[24] H. Al-Ekabi and N. Serpone, Langmuir 5 (1989) 250. 